\title{
Palaeopathology and Differential Diagnosis-A Probable Case of Secondary Infection (Tell Masaikh, Syria)
}

\author{
Jacek Tomczyk $^{1 *}$, Hanna Mańkowska-Pliszka ${ }^{2}$, G. Michael Taylor ${ }^{3}$, Ron Pinhasi ${ }^{4}$, \\ Maciej Jakuciński ${ }^{5}$ \\ ${ }^{1}$ Department of Anthropology, Cardinal Stefan Wyszynski University, Warsaw, Poland \\ ${ }^{2}$ Department of Descriptive and Clinical Anatomy, Medical University of Warsaw, Poland \\ ${ }^{3}$ Division of Microbial Sciences, Faculty of Health and Medical Sciences, London, UK \\ ${ }^{4}$ Department of Archaeology, University College Cork, Cork, Ireland \\ ${ }^{5}$ Institute of Nuclear Medicine and Magnetic Resonance, Brudnowski Hospital, Warsaw, Poland \\ Email: jaktom@post.pl
}

Received November 20 $0^{\text {th }}, 2012$; revised December 21 $1^{\text {st }}, 2012$; accepted January $3^{\text {rd }}, 2013$

\begin{abstract}
Palaeopathology integrates knowledge and methods from physical anthropology and medicine. It aims to obtain information concerning the type of pathological conditions, their antiquity, palaeoepidemiology and etiology in past populations. However, practice shows that despite the use of new techniques, it is often difficult or impossible to make a correct differential diagnosis of diseases based on the study of archaeological skeletal series. Here we present a case study of differential diagnosis of pathological conditions which have been observed on the bones of the skeleton of a 30 - 34 years old female from Tell Masaikh (Syria). Morphological, histological, radiological and molecular methods have been applied in order to assess the pathological lesions. The molecular analysis shows no evidence of Mycobacterium tuberculosis although this should be regarded as absence of evidence and not evidence of absence. Subsequently our diagnosis was narrowed to traumatic changes related to infection. This illustrates the complications associated with differential diagnosis of pathological conditions from ancient bones.
\end{abstract}

Keywords: Palaeopathology; Syria; Tuberculosis; Infection

\section{Introduction}

Palaeopathological analysis constitutes a significant part of anthropological research as it allows researchers to obtain information and gain knowledge about disease and health in past populations as well as on the antiquity, prevalence and etiology of certain conditions. However, practice shows that differential diagnosis of many conditions is often difficult or impossible due to taphonomic aspects such as the preservation of bone and the degree of completeness/fragmentation of certain skeletal features. For this reason, in many cases palaeopathological analysis can only narrow down the diagnosis to one or more possible conditions. In this paper we present a case study of differential diagnosis of pathological conditions which have been observed on the bones of the skeleton of a 30 - 34 years old female from Masaikh, Middle Euphrates Valley, Syria.

\section{Material}

During the excavation season of 2006/2007 an almost complete skeleton of a female (MK 11EN28) with numerous pathological changes was excavated in Tell Masaikh (Syria). The archaeological site is located on the left bank of the Euphrates, some $6 \mathrm{~km}$ upstream of Terqa (modern Tell Ashara). The tomb fill contained some ceramic sherds from the Late Roman period $\left(2^{\text {nd }}-4^{\text {th }}\right.$ century $\left.\mathrm{AD}\right)$, and hence gives a terminus post quem date to the skeleton. Based on the pottery and on the chronology of the site (tell), the skeleton dates to the period between end of Late Roman and beginning of the Early Islamic period

\footnotetext{
* Corresponding author.
}

$\left(10^{\text {th }}-12^{\text {th }}\right.$ century AD) (Masetti-Rouault, 2008) (Figure 1).

The skeleton was discovered and studied in the anthropological laboratory in Tell Ashara, and some samples were prepared for analyses in specialist laboratories. The sex of the individual was determined on the basis of the Phenice method (cf. Buikstra \& Ubelaker, 1994). The age of the individual was estimated on the basis of changes in the morphology of the pubic symphysis using the Brooks and Suchey (1990) system and standards for changes in the topography of the auricular surface (cf. Buikstra \& Ubelaker, 1994; White \& Folkens, 2000). Based on these criteria the individual represents female, the age of death was assessed as $30-34$ years.

\section{Methods}

All of the bones were examined macroscopically using available light sources and any signs of pathological alternations were recorded following the methodology described by Buikstra and Ubelaker (1994).

Histological preparations were made in order to identify the disease observed macroscopically on the remains of the female individual from Tell Masaikh. Histological analysis was conducted in two independent research centers (Department of Patomorphology, Specialist Hospital in Siedlce, Poland and Department of Descriptive and Clinical Anatomy, Medical University of Warsaw, Poland) in order to obtain two independent sets of results. Histological slides were prepared from sections taken from the first metatarsal bone, calcaneus and proximal epiphysis of fibula of the left leg as these show distinct patho- 


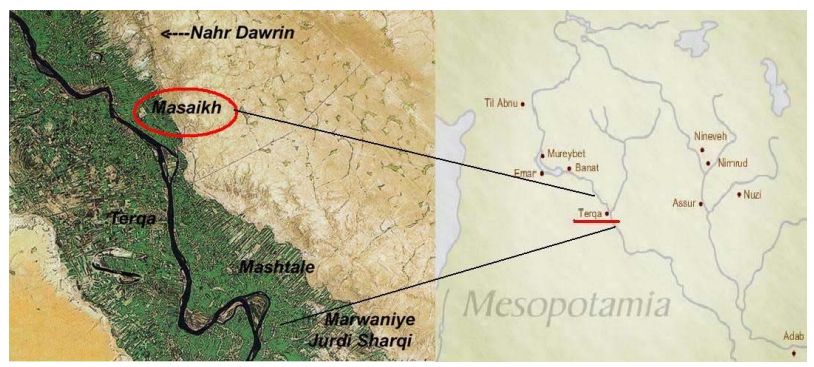

Figure 1.

Map of the excavation area.

logical changes, similar to the other bones from the left side of the skeleton. Observations were carried out using a BX $41 \mathrm{M}$ Olympus microscope.

Radiological examinations were performed in the Institute of Nuclear Medicine and Magnetic Resonance, Brudnowski Hospital, Poland, and the Radiological Diagnostic Centre in Maiadin, Syria. Images were all in anterio-superior projection and the period of exposure was set to 1.2 seconds. In these tests we used the left femur, tibia and fibula and the first left metatarsal. The latter was analyzed in Poland while the former were analyzed in Maiadin (Syria) due to their (pathological) brittle condition.

DNA extractions: bone samples from the left second metatarsal were pulverized to a fine bone powder before analysis. A NucliSens ${ }^{\mathrm{TM}}$ kit from bioMérieux (bioMérieux UK Limited, Hampshire, UK) was used to extract DNA, with minor modification to the manufacturers' protocol. The bone powder sample was placed into pre-weighed tubes containing 0.5 g glass beads (Sigma G8893, <106 $\mu \mathrm{m}, 140$-finer US sieve). Lysis buffer from the kit $(0.9 \mathrm{ml})$ was added and the samples additionally sealed with parafilm ${ }^{\circledR}$ and then subjected to agitation for 10 minutes at room temperature on a vortex mixer with a beadbeating adapter. The samples were also subjected to 3 freezethaw cycles in liquid nitrogen to facilitate recovery and solubilisation of DNA. After centrifugation at $10.000 \times \mathrm{rpm}$ for 5 minutes the supernatants were removed and transferred to new $2 \mathrm{~mL}$ microcentrifuge tubes to which the silica slurry $(40 \mu \mathrm{l})$ was added. The samples were mixed on a rotator wheel (Stuart, model SB2) for 20 minutes to allow binding of DNA to the silica. Thereafter, the manufacturer's instructions for washing and elution of the DNA were followed. The residues were eluted from the silica with $60 \mu \mathrm{l}$ molecular biology grade water. Five microlitre aliquots of the extract were used in PCR reactions. The extracts were screened for evidence of DNA from the Mycobacterium tuberculosis complex. The multi copy elements IS1081 were the loci targeted for tuberculosis. The intercalating fluorophore SYBR Green was used to monitor all the PCR reactions. Additionally, the formation of any specific IS1081 amplicons in the MTB assay was monitored using a dual-labelled hybridisation probe. Real-time PCR was performed in a final volume of $25 \mu \mathrm{l}$ using the Excite Core kit from Biogene Ltd., Cambridge, UK. The reactions contained 25 pmol of the forward and reverse primers in $1 \mu 1,2.5 \mu 1$ of $10 \times$ reaction buffer, 2 - $3 \mu \mathrm{lgCl}_{2}, 2.5 \mu \mathrm{l}$ bovine serum albumin (non-acetylated, BSA, Sigma B4287), $5 \mu 1$ of template and 0.5 $\mathrm{U}$ of Taq polymerase. The volumes were made up to $25 \mu 1$ with water (VWR International). After an initial denaturation step (8 min at $\left.95^{\circ} \mathrm{C}\right), 45$ cycles of amplification were performed as follows: denaturation at $95^{\circ} \mathrm{C}$ for $10 \mathrm{~s}$, annealing (at $60^{\circ} \mathrm{C}$ for
IS1081) for $30 \mathrm{~s}$, extension at $72^{\circ} \mathrm{C}$ for $20 \mathrm{~s}$. SYBR Green $(2.5$ $\mu 1)$ was included in all experiments at a final dilution of $1 / 55.000$ and reactions were performed and monitored on a Corbett Rotor-Gene 3000 real-time PCR platform. Melt analyses were performed automatically at the end of the run with the Rotor-Gene software and all products were also run out on 3\% agarose checker gels. When the IS1081 hybridisation probe was included, this was used at a final concentration of $100 \mathrm{nM}$, through the addition of $1 \mu \mathrm{l}$ of a $2.5 \mu \mathrm{M}$ working stock of probe per $25 \mu 1$ reaction. For these experiments, the magnesium concentration was increased to $3 \mathrm{mM}$ and data was acquired at $76^{\circ} \mathrm{C}$ for $60 \mathrm{~s}$. Template blanks containing water in place of DNA extract were always included, but positive controls were omitted to avoid the possibility of cross contamination.

\section{Results}

All the observed distinct palaeopathological changes were only affecting the left side of the specimen. Cribra orbitalia was detected on both orbital roofs. Using the revised version of Nathan and Haas (1966) and Stuart-Macadam's (1985) criteria we observed cribrotic type $\mathrm{Nr} 2$ (small as well as large and isolated foramina). On the left acromion, the structures of the trabeculi are slightly thinned with remodeling and hypertrophic bone development. A few ribs from both sides showed subtle periosteal reaction on their midshafts and proliferation of new bone on visceral surfaces. The left ilium (ala ossis illi) has some damage which is particularly visible on the medial aspect: the auricular surface and arcuate line. Bone from the affected side was very fragile and light when compared with this from the opposite side. Although the observed destruction is mechanical (post-mortem), it was facilitated by earlier thinning of the periosteal and cortical layers. We observe thinning of the periosteal and cortical layers on the left pubic bone, especially on the inferior ramus. Additional pathological changes were detected on the lower left limb. The entire femur is very fragile with evidence of thinning of the cortical bone and serious damage of the trabecular bone. There are numerous enthesophytes on the posterior side of the femoral shaft which originate at the linea aspera and continue along the superior part of the bone (Figure 2).

The structure of the enthesophytes is heterogeneous and they accrete in some places. Their macrostructure is strongly perforated with losses of sub-cortical basal parts. A few large cavities $(5 \mathrm{~mm} \times 2 \mathrm{~mm})$ with obliterated edges are observed on the neck of the femur. However, both trochanters of the femur are completely destroyed due to thinning of the cortical bone. Radiography shows a widening of the femoral cortical bone, and the dilution of the substance in the metaphysis. The left patella is very fragile with various enthesophytes arranged in parallel on its anterior surface, whereas the articular surface (facies articularis) is seriously damaged, enlarged and contains numerous perforations (Figure 2).

The left tibia has considerable damage of the cortical and trabecular bone.

However, the most extensive deformation is not evident on the diaphysis, as in the case of the left femur, but on its epiphyses. These changes consist on quantitative deficiency of the cortical structure what is connected with the rarefaction of this area. Many osteophytes originate from both condyles (though there are more of them from the medial condyle-condylus medialis), and their maximum length is $29 \mathrm{~mm}$. The superior 

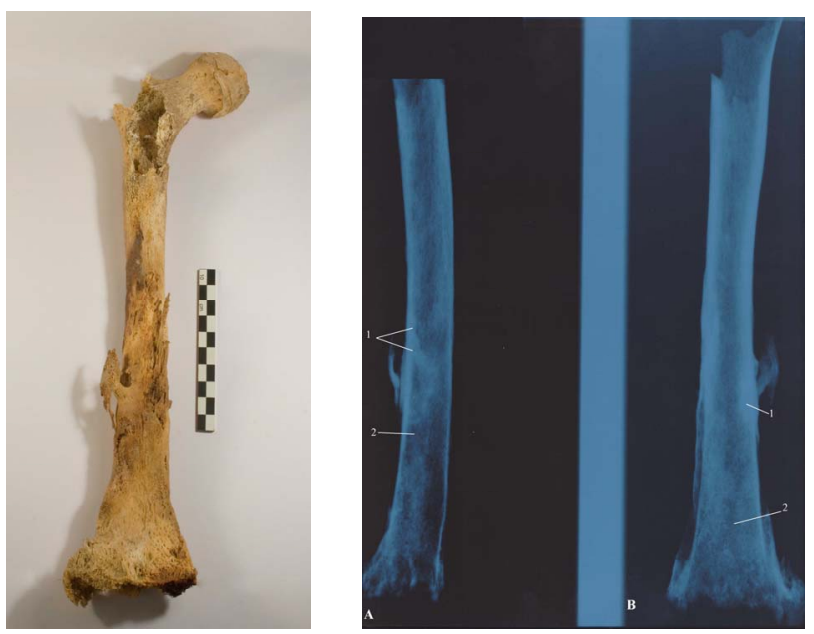

Figure 2.

Femur with pathological changes (posterior view) and radiograph of femur (A: medial view; B: anterior view): 1: widening of cortical bone; 2: dilution of the substance.

articular surface (facies articularis superior) is very fragile and completely perforated (spongy). Moreover, enthesophytes appear above the nutrient foramen (foramen nutricium). The radiograph of the left tibia reveals irregular lytic changes on the surface of the proximal epiphysis with segmental densification of the osseous structures. On the edge of the proximal epiphysis there are irregular layers which are orientated towards the tibial diaphysis. There are also small signs of periosteal ossification (or myositis ossificans), which may indicate post-traumatic changes as compared to post-inflammatory changes (Figure 3).

The left fibula is damaged. The shaft of the bone is partially broken at the midshaft, caused by post-mortem damage. The fracture was, however, facilitated by structural ante-mortem changes - thinning of the cortical layer and fragmentation of the trabecular bone. Certain hypertrophic bone development is observed in the proximal epiphysis. The articular surface of the head (facies articularis capitis fibulae) is barely noticeable due to deformations. The margins underwent destructive remodeling with reactive woven-bone formation at the midshaft. The hypertrophic bone located in the upper parts of the shaft is inferiorly oriented while those from the distal section are superiorly oriented. The distal epiphysis of the left fibula is completely damaged. The radiographs of the fibula show osteolytic changes in the cortical layer and the presence of enthesophytes. Remodeling in the proximal metaphyseal segment can be observed, which may indicate past traumatic damage and/or fracture. The preserved bones of the left foot display pathological features. The external surface of the calcaneus is completely porous. On the calcaneal tuberosity there are cone-shaped osseous exostoses. All the articular surfaces are perforated and enlarged. Certain damage can also be observed on the metatarsal and on the phalanges. We observed hypertrophic bone development in the proximal phalanx of the big toe. It is characterized by a long moon-shaped osseous overhang $27 \mathrm{~mm}$ long, located on the lateral side of the proximal epiphysis (Figure 4).

Radiological images show stimulation of resorptive and atrophic processes concerning the trabecular tissue of first left metatarsal bone. Medially, two post-inflammatory niches (abscesses) are visible - the size of the first one is $2 \mathrm{~mm}$ and the other one is $5 \mathrm{~mm}$. Similarly, in the lateral part there is a crypt
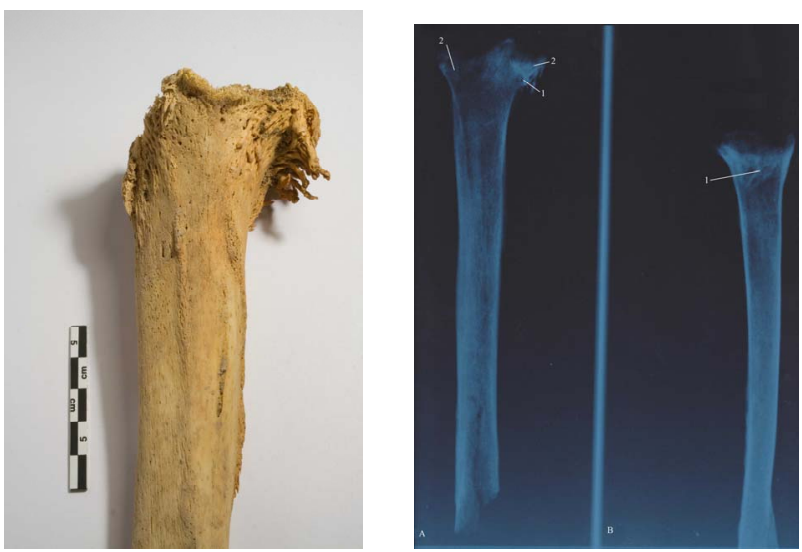

\section{Figure 3.}

Tibia (posterior view) and radiograph (A: posterior view; B: medial view): 1: segmental densification of the osseous structures; 2: postinflammatory changes.

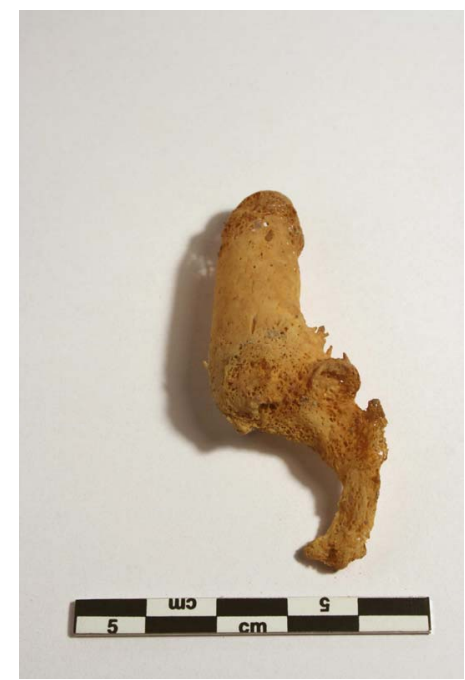

\section{Figure 4.}

The big toe with a long moon-shaped osseous overhang.

$(2 \mathrm{~mm})$ of the same origin as the niches in the medial part (Figure 5).

Initial experiments $(n=2)$ aimed at detecting MTB complex DNA using the IS1081 F2/R2 primer pair, which would amplify a 135 bp product, were negative, whether assessed using the hybridisation probe or SYBR Green followed by melt analysis. Similarly, an attempt to detect a shorter fragment length (113 bp) using the primer combination of F2/R3 was also negative. To confirm the real-time data, all PCR reactions were also analysed by gel electrophoresis on 3\% agarose gels. This confirmed the real-time analysis. Formation of primerdimer and occasional non-specific bands were seen but no bands of expected size for either pathogen loci were found (not shown). The IS1081 screening method is extremely sensitive and detect less that one genome equivalent ( $>1$ GE, Taylor, Watson, Lockwood, \& Mays, 2006; Taylor, Worth, Palmer, Jahans, \& Hewinson, 2008). At the end of the aDNA analyses, positive control for MTB was run in the same assay systems to check the PCR reaction components. This template was readily detected. Unfortunately therefore, we conclude that our at- 


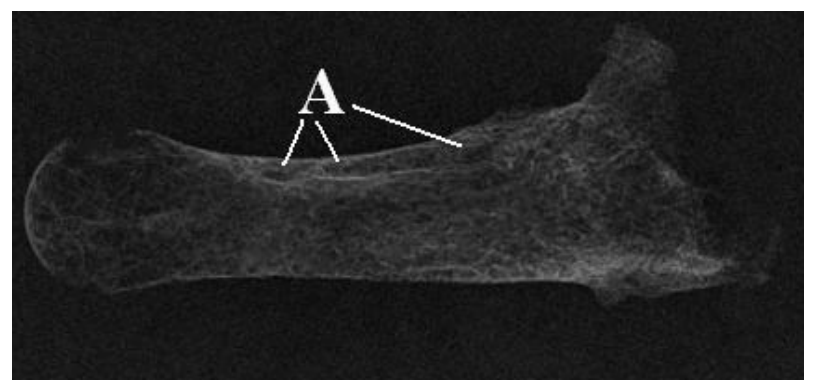

Figure 5.

The first left metatarsal bone of the phalange: A: two post-inflammatory niches.

tempts to use PCR to demonstrate remnant DNA from either pathogen in this case were unsuccessful. Therefore it seems less likely that either disease was active at the time of death. However, we cannot categorically rule out poor DNA preservation as an explanation for the negative findings in this case.

\section{Discussion}

The study of the individual reveals a complex picture. So the discovery with the extensive pathological changes is particularly interesting. The macroscopic assessment indicates that the entire left limb and pelvis is pathologically altered, starting from the left ilium to the phalanges of the left foot. Minor changes can also be seen on the ribs, left scapula and clavicle. The bones display evidence of osteoporosis, hypertrophic bone with the osseous exostoses.

The subtle bone damage (especially on the ribs) may be associated with MTB. Palaeopathological study of MTB in human remains has been carried out for nearly 100 years (Stone, Wilbur, Buikstra, \& Roberts, 2009). But in the last two decades a considerable progress has been made in palaeopathological and biomolecular analysis of the disease/pathogen, indicating that MTB prevailed since prehistory (e.g. Canci, Minozzi, \& Borgognini Tarli, 1996; Zink, Haas, Reischl, Szeimies, \& Nerlich, 2001; Mays, Fysh, \& Taylor, 2002). MTB is caused by a group of closely related bacterial species called the M. tuberculosis complex. Other bacterial species are widespread in the environment but members of the MTB complex are obligate pathogens. The principal cause of human tuberculosis is $M$. tuberculosis. In this case infection occurs via droplet infection. Humans can also become infected by $M$. bovis. But it is estimated that $M$. bovis is responsible only for about $6 \%$ of human tuberculosis cases (Hardie \& Watson, 1992; Rost, 1995). MTB relates to people of all ages, although in most cases the archaeological material concerns, for obvious reasons, the skeletons of juveniles (Santos \& Roberts, 2001; Ortner, 2003, 2008; Stone, Wilbur, Buikstra, \& Roberts, 2009). Our initial suspicions about MTB resulted from the macroscopic inspection of the long bones, especially of the changes in the metaphyseal areas, and the ribs. In the first case, destruction of the osseous structure and intensified bone neoplasial processes were observed. In the ribs subtle bone damage connected with periosteal reaction and proliferation of new bone on visceral surface. Moreover, our attention was riveted by the changes within the pelvis - the compact tissue defect and the osteoporosis. Some authors admit (e.g. Ortner, 2003) that changes in this area, identified with MTB sacroilitis, occur more frequently in young adults (between 20 and 30 years old) than with children, which corresponds to the age of the individual described. Of course, discreet bones damage which may be associated with MTB is not described as a diagnostic criterion. However, in this case study, no pathological changes were observed on the spine. So we have taken advantage molecular and radiological researches to confirm or exclude suspicion of MTB. However, our macroscopic observations were not confirmed - either by radiological or molecular means.

Susceptibility to infections (bacterium, virus) and the progression of the infection is to a large extent depending on the effectiveness of the immune system. The infections might result in death, latent, or chronic disease. Bone tissue is affected by infection that lasts longer than a few weeks. In our case study, it is likely that we are dealing with an infection of bacterial origin arising from local trauma to the ankle and/or knee regions. The radiographic study of the tibia shows irregular lytic changes which are observed on the proximal epiphysis. In the proximal head of the tibial bone there are slight signs of periosteal reaction, which may indicate post-traumatic change. Moreover, we observe the osteolytic changes in the cortical layer in the fibula. The specimen from Tell Masaikh seems to have suffered from serious traumatic changes (e.g. open fracture) related to a secondary infection with suppurative inflammation. The infection maybe was started in the knee region, and then infected the rest of the left leg via the blood stream. But we cannot, however, exclude other potential scenarios in which the infection affected other bones from a primary location via the blood stream. As mentioned above, we found three post-inflammatory niches in the first metatarsal. Moreover, radiologically, there is visible thinning of the cortical layer with complete local atrophy. This area could be an outbreak of inflammation. The degeneration of the osseous tissue due to osteolytic processes and its later irregular reconstruction is especially well visible in the histological picture. The osseous trabeculas in this case are thinned and their number often decreases in relation to the normal osseous mass. The decalcified bone tissue does not have a margin. Our histological analysis shows Haversian canals, not so numerous in the cortical part, which are enlarged. This fact indicates disturbances in the distribution of the blood in the bones. These may be the results of a secondary bacterial infection.

\section{Conclusion}

Palaeopathological research is an important element of bioarchaeological research. Practice, however, shows that the differential diagnosis of pathological conditions observed in archaeological material is often fraught with difficulties. This case study demonstrates how the use of various laboratory methods, together with systematic macroscopic assessment, is essential for diagnosis of certain cases. The individual from Tell Masaikh is a case in point — our approach led to the identification of some possible medical conditions associated with the observed pathological changes (which are however, not mutually exclusive): MTB and serious traumatic changes subsequent to a secondary infection. Ancient DNA evidence for the MTB complex was not detected, making this diagnosis less likely. However, we cannot rule out poor DNA survival for this observation. Our analysis suggests that the most probable conditions which fit the distribution and the type of observed changes are traumatic changes and associated secondary infection. 


\section{Acknowledgements}

The authors would like to thank Professor Judyta Gładkowska-Rzeczycka from Gdańsk (Poland) who has accompanied our research from the very start and has given us much advice and additional information. We also direct our words of gratitude to Professor Leszek Królicki from the Institution of Nuclear Medicine and Magnetic Resonance at Brudnowski Hospital in Warsaw for allowing us to use a computer scanner and an X-ray machine. Professor Królicki was also willing to share his own observations and remarks. Many thanks are also dedicated to the medical staff-Dr. Haider Esmail from Ashara and Dr. Hawash Eliane from Maiadin (Syria) who helped to perform X-ray tests of materials.

The research was financed by the Ministry of Science and Higher Education (Poland) during years 2009-2011 under Grant No. N303 319837.

\section{REFERENCES}

Brooks, S. T., \& Suchey, J. M. (1990). Skeletal age determination based on the os pubis: A comparison of the Acsádi-Nemeskéri and Suchey-Brooks methods. Human Evolution, 5, 227-238. doi:10.1007/BF02437238

Buikstra, J. E., \& Ubelaker, D. H. (1994). Standards for data collection from human skeletal remains. Arkansas Archeological Survey Research Series, 44, Fayetteville.

Canci, A., Minozzi, S., \& Borgognini Tarli, S. M. (1996). New evidence of tuberculous spondylitis from Neolithic Liguria (Italy). International Journal of Osteoarchaeology, 6, 497-501. doi:10.1002/(SICI)1099-1212(199612)6:5<497::AID-OA291>3.0.C O;2-O

Hardie, R. M., \& Watson, J. M. (1992). Mycobacterium bovis in England and Wales: Past, present and future. Epidemiology \& Infection, 109, 23-33.

Massetti-Rouault, M. G. (2008). Rapporto preliminare sui lavori della missione nel sito di Tell Masaikh (MK11). Athenaeum-Studi di
Letteratura e Storia dell'Antichità, Università di Pavia, 96, 914-915.

Mays, S., Fysh, E., \& Taylor, G. M. (2002). Investigation of the link between visceral surface rib lesions and tuberculosis in a Medieval skeletal series from England using ancient DNA. American Journal of Physical Anthropology, 119, 27-36. doi:10.1002/ajpa.10099

Nathan, H., \& Haas, H. (1966). "Cribra orbitalia". A bone condition of the orbit of unknown nature. Anatomical study with etiological considerations. Israel Journal of Medical Sciences, 2, 171-191.

Ortner, D. J. (2003). Identification of pathological conditions in human skeletal remains (1st ed.). London: Academic Press.

Ortner, D. J. (2008). Differential diagnosis of skeletal lesions in infectious disease. In R. Pinhasi, \& S. Mays (Eds.), Advances in human palaeopathology (pp. 191-214). Chichester: John Wiley \& Sons, Ltd.

Rost, R. (1995). TB or not TB: The new world question. Totem: The UWO Journal of Anthropology, 2, 54-59.

Santos, A. L., \& Roberts, C. A. (2001). A picture of tuberculosis in young Portuguese people in the early $20^{\text {th }}$ century: A multidisciplinary study of the skeletal and historical evidence. American Journal of Physical Anthropology, 115, 38-49. doi:10.1002/ajpa.1054

Stone, A. C., Wilbur, A. K., Buikstra, J. E., \& Roberts, C. A. (2009) Tuberculosis and leprosy in perspective. Yearbook of Physical Anthropology, 52, 66-94. doi:10.1002/ajpa.21185

Stuart-Macadam, P. (1985). Porotic hyperostosis: Representative of a clinical childhood condition. American Journal of Physical Anthropology, 66, 391-398. doi:10.1002/ajpa.1330660407

Taylor, G. M., Watson, C. L., Lockwood, D. N. J., \& Mays, S. A. (2006). Variable nucleotide tandem repeat (vntr) typing of two cases of lepromatous leprosy from the archaeological record. Journal of Archaeological Science, 33, 1569-1579. doi:10.1016/j.jas.2006.02.008

Taylor, G. M., Worth, D. R., Palmer, S., Jahans, K., \& Hewinson, R. G. (2008). Rapid detection of Mycobacterium bovis DNA in cattle lymph nodes with visible lesions using PCR. BMC Veterinary Research, 3, 12. doi:10.1186/1746-6148-3-12

White, T. D., \& Folkens, P. A. (2000). Human osteology (2nd ed.). San Diego: Accademic Press.

Zink, A., Haas, C. J., Reischl, U., Szeimies, U., \& Nerlich, A. G. (2001). Molecular analysis of skeletal tuberculosis in an ancient Egyptian population. Journal of Medical Microbiology, 50, 355-366. 